\title{
Clinical and pathological study of retained placenta in Iraqi buffaloes

\author{
$\begin{array}{lll}\text { E. R. Al-Kennany } & \text { M. A. Rahawy } & \text { E. S. Al-Allaf }\end{array}$ \\ Coll. of Vet. Med./ Unive. of Mosul
}

\begin{abstract}
The present study was conducted to explore the clinical signs and pathological changes might occur with retained placenta. Sixty three placenta examined of Iraqi buffaloes in Ninavah province during the period from February 2005 to February 2006, were collected after $24 \mathrm{hr}$ post partum, Result showed variable gross lesions in those examined placenta. Some retained placenta showed sever congestion associated with presence of focal areas of necrosis and, others suffer from thickening with congested some of cotyledons. Histologically, the lesions characterized by thickening in wall of maternal blood vessels and, coagulative necrosis appeared in placental plates, maternal caruncles and fetal cotyledon. Infiltration and proliferation of macrophages and binucleated cells, desquamation of syncytiotrophoblast was quite ovious. Moreover, most Retained Placenta sections has revealed dystrophic calcification association with fatty infilteration.

Retained Placenta defined as the condition in which the fetal membrane are not expelled from the uterus within period of $12-24 \mathrm{hr}$ after expulsion of the fetus (1). It is economically one of the most important disturbance during the postpartum period because it affected hard health, milk production and reproduction efficiency (2). Retained Placenta is observed (16.03\%) from reproductive disorders in Iraqi buffaloes (3). The retention of fetal

\section{Introduction}

membranes can be a substantial risk factor for toxic puerperal metritis in buffaloes (4). Retained Placenta in buffaloes causes significant pathological studies on the Retained Placenta of buffaloes have been documented previously (5) few studies remarked Retained Placenta in buffaloes, therefore, the aim of this study was determined the relationship between clinical signs and the histopathological changes of Retained Placenta in Iraqi buffaloes.
\end{abstract}

\section{Material and Methodes}

The current study was conducted on 63 Iraqi Buffalo cows (Bubalus bubalis) suffering from Retained Placenta after normal parturition (48 Buffalo cows) and dystocia (15 Buffalo cows), in Ninavah province during the period from February 2005 to February 2006. Clinical examinations were included case history, general examination, rectal palpation and vaginal examination. Retained fetal membranes were collected from animals included in the study after 12-24 hr postpartum. Samples of placenta were collected and fixed in 10\% neutral buffered formalin for $48 \mathrm{hr}$. The tissue specimences were dehydrated in graded series of alcohol and cleared by xylole then embedded in paraffin. Histological sections were cut into $4-5 \mathrm{Mm}$ thickness and stained with haematoxyline and eosin stain H\&E (6).

\section{Results}

Clinical signs: of Retained Placenta included depression, restlessness, arched back with straining, dysurea, diarrhea, reduce milk secretion, loose appetite, slightly increase rectal temperature $(38.4+0.03)$ while $(38.1+0.4)$ in normal expelled placenta, increase respiration rate
$(39.1+1.7$ per $\mathrm{min})$ while $(37.2+1.37$ per min) in normal, pulse rate $(73.4+1.9$ per min), Varies amount of placental retention depends mainly on attached parts of placenta to the uterine caruncal. Cervical involution was decreased slowly when buffaloes having retention of fetal membranes, from $>7.5 \mathrm{~cm}$ 
diameter to $5 \mathrm{~cm}$ after 3 day postpartum, while normal buffalo with no retention of fetal membrane(Fig 1) the cervical diameter was decreased to $5 \mathrm{~cm}$ after $24 \mathrm{hr}$ postpartum. This observation was conformed during cervical manipulation per vagina. Fetid odor was observed mainly after $72 \mathrm{hr}$ postpartum in buffalo affected with Retained Placenta. Vaginal discharge was mainly bloody brown after $24 \mathrm{hr}$ postpartum and the change to watery black bloody discharge after $48 \mathrm{hr}$ postpartum. After $72 \mathrm{hr}$, the discharge was changed to watery brown color with offensive odor.

Gross pathological changes: gross pathological lesion characterized by presence of sever congestion, with focal area of necrosis about $0.2-0.5 \mathrm{~cm}$ in diameter and thicking in cotyledon as compare with normal placenta which have no pathological lesion.

Histopathological changes: histological section of normal placentae from buffalo do not show any pathological changes while histological sections of Retained Placenta revealed focal area of coagulative necrosis in placental plate, (Fig2), atrophy of some carunculous desquamation of syncytiotrophoblast to accumulate as knot also have been (Fig3) some other section illustrated vascular change represented by hemorrhage, congestion, thromboses and edema associated with hyaline degeneration and thickens in the wall of blood vessels sclerosis (Fig 4). On other hand, some sections revealed coagulative necrosis in cotyledon which become eosinophilic unstructural mass (Fig 5) associated with proliferation and inflammatory cells like numerous neutrophilic and macrophage in placental connective tissues between villous as well as calcification\& fatty infiltration and proliferation of binucleated cells have been seen (Fig 6).
Signs concomitant with Retained Placenta that seen in our study included restlessness, arched back with straining, dysurea, diarrhea, reduce milk secretion may be similar that reported by (7) Placental section in Retained Placenta of Iraqi buffaloes demonstrated variable histopathological lesions.like Placentitis, that seen occurs in this study may be similar to that reported previously in cattle $(8,9)$. This lesion may be due to disturbance on the release of the fetal (cotyledon) from the maternal (caruncal) unit. However, it has been reported that several local factors might be involved in the etiology of Retained Placenta during the cascade of endocrine event initiated by increased total adrenal cortisol secretion, maturation of the fetal hypothalamus-pituitary-adrenal axis $(10,11)$. Vasculitis seen in buffaloes Retained Placenta, may be induced due to release of endotheline-1 and endothelial cell-derived vasconstrictive peptide, in response stimulation of the uterus during labor and

\section{Discussion}

delivery in human and rats (12). There is alot, evidence supporting the existence of local tissue renin-angiotensin systems in the uteroplacental unit (13) that contribute to Retained Placenta Animals having Retained Placenta showed proliferation in polymorphnucles cells such as neutrophiles and mononuclear cells, e.g. lymphocytes, macrophage and binucleated cells, these cells have playing an important role in expullsion of placenta. (14) reports the role of the immune system in expulsion of placenta they found that myeloperoxidase activity, as enzyme in neutrophils, was involved in tissue rejection and killing neutrophils isolated from blood of cow with Retained Placenta, In addition it has been reported that cow with Retained Placenta had lower blood level of interleukin- 8 which is a chemo attractant compound found in the placental cotyledon, reduced ability of the neutrophils to recognize the placental tissue as foreign and by there expel it from uterus bloody brown vaginal discharge after $48 \mathrm{hr}$ 
postpartum and change to watery brown color with offensive odor, also have been seen in this study, this evidence may induced due to putrefactive process proceeds in uterus. These results that reported above an Retained Placenta may be accompanied by metritis or other factors that contribute for induction of Retained Placenta. Recent studies suggest that Retained Placenta might have a relationship with releasing of oxygen free radical that cause oxidative stress, thus and excess might be dangerous for cells and tissue (15). There is evidence that some parameters of oxidative stress are altered in case of Retained Placenta as compared to properly released placenta(16) which need more further studies in buffalo cow.

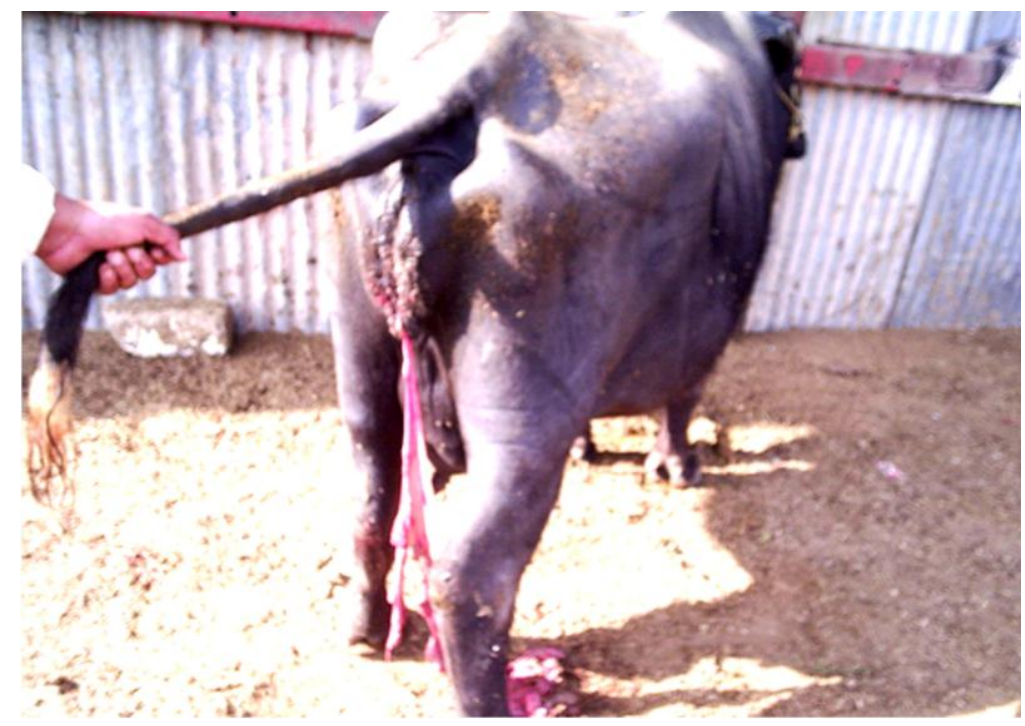

Fig 1: Iraqi buffalo, showed Retained Placenta.

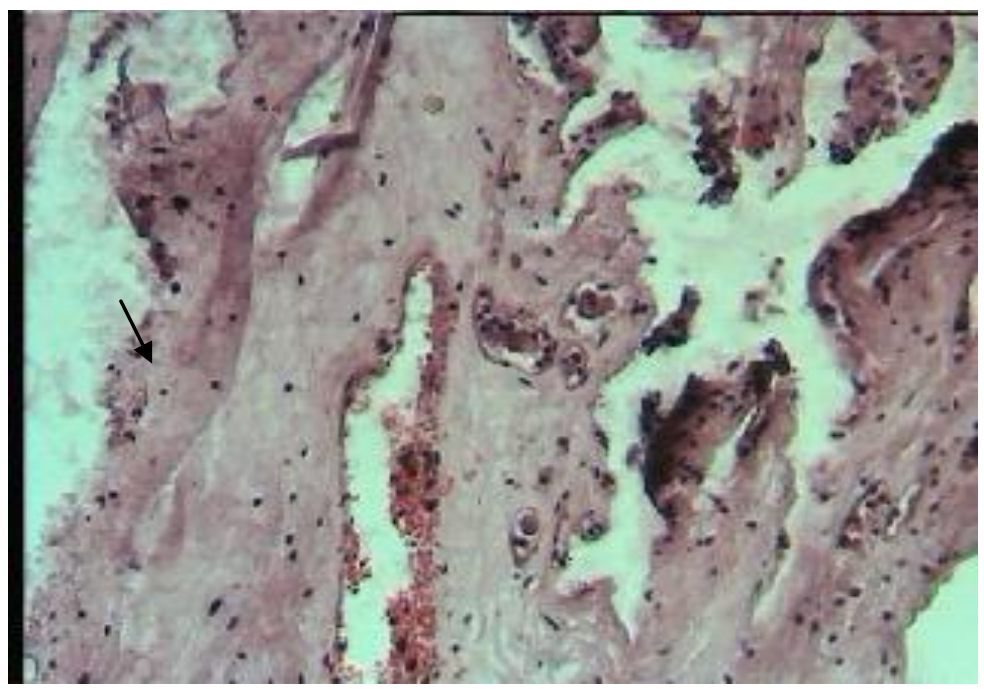

Fig2: Histological section form Retained Placenta of buffalo revealed deposition of calcium salt (Dystrophic calcification in placental villi) associated with desquamation of syncytiotrophoblast as knot (arrow). H\&E (400X) 


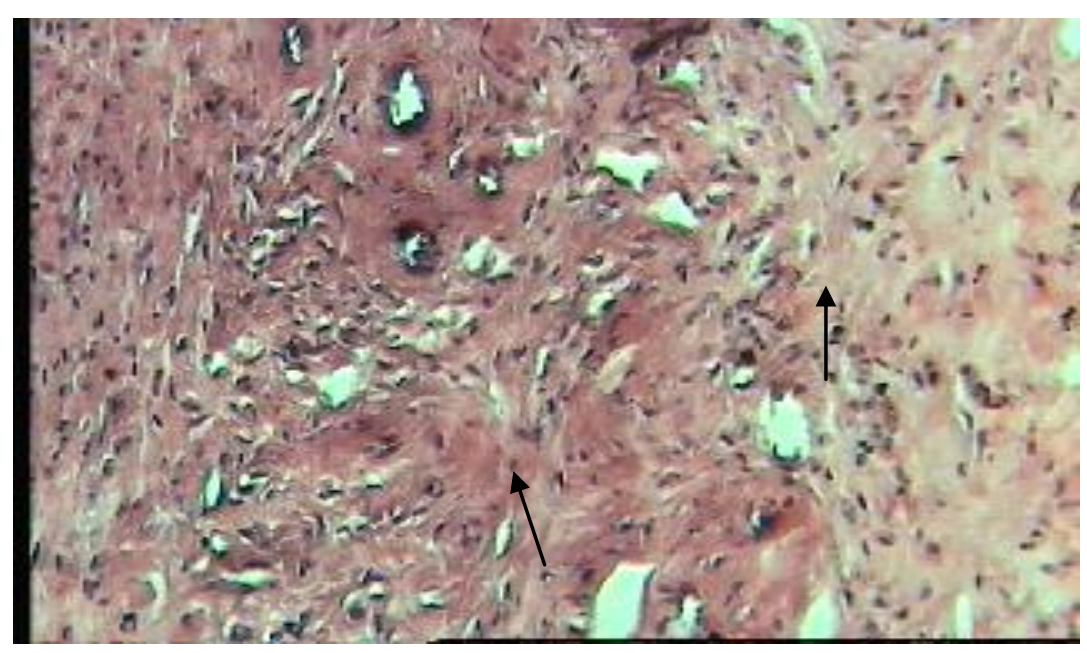

Fig3:Histological section form Retained Placenta of buffalo showed, necrosis, infiltration of mononuclears inflammatory cells (arrow) H\&E 400X.

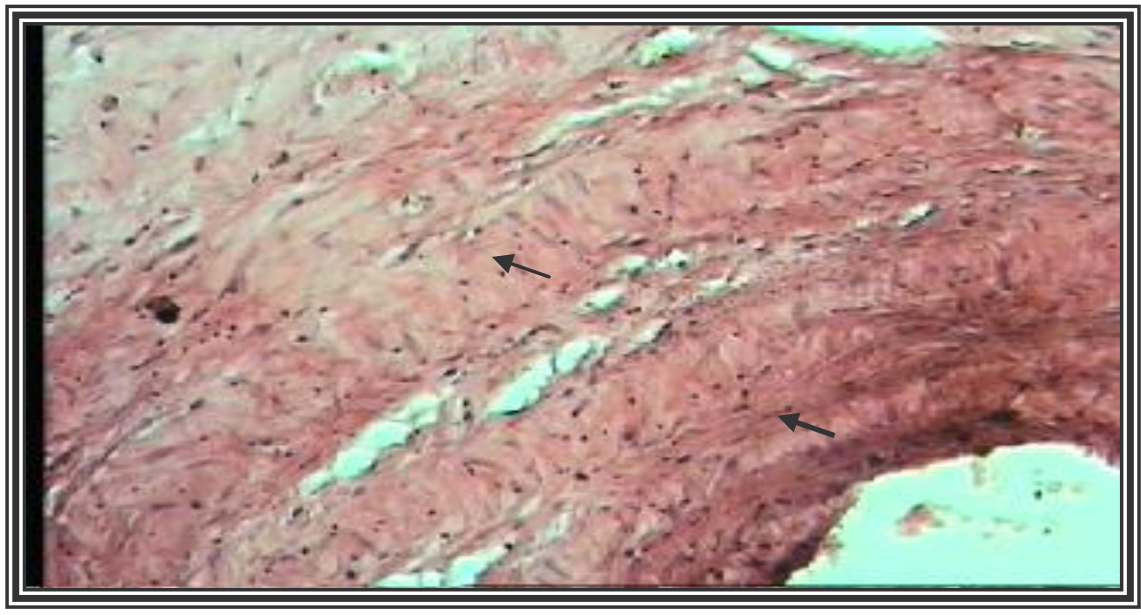

Fig 4: Histological section form Retained Placenta of buffalo revealed thickness in wall of maternal blood vessels(artery) associated with hyaline degeneration (arrow). H\&E 400X

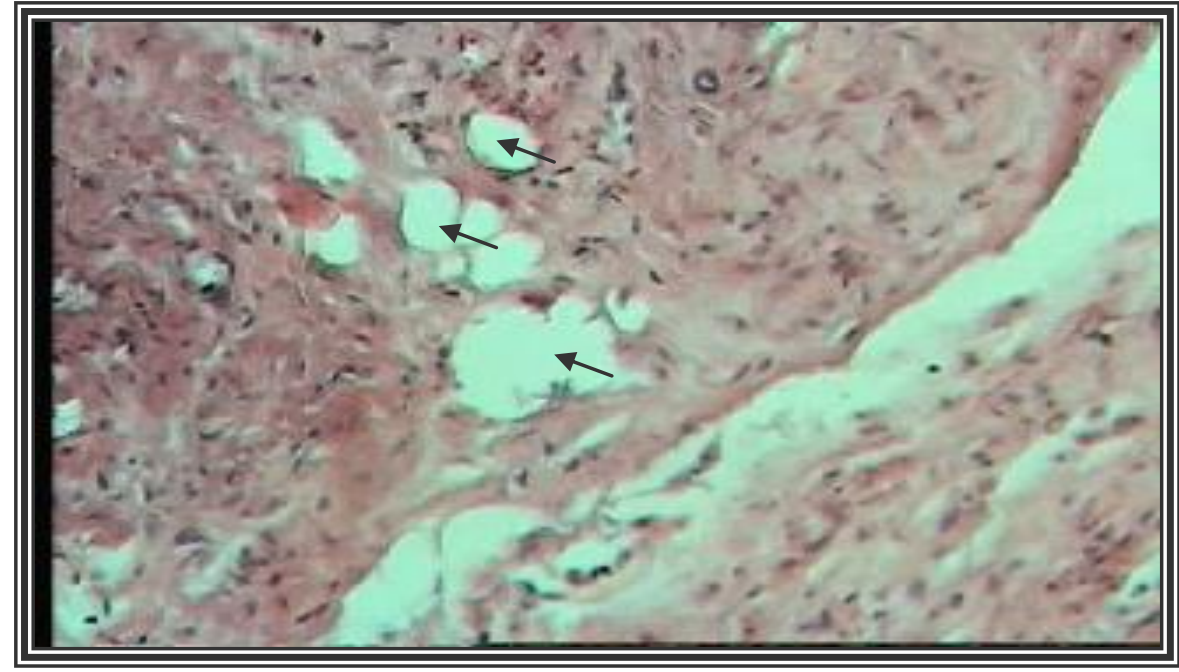

Fig 5: Histological section from Retained Placenta of buffalo showed fatty change in placental connective tissue (arrow). H\&E 400X. 


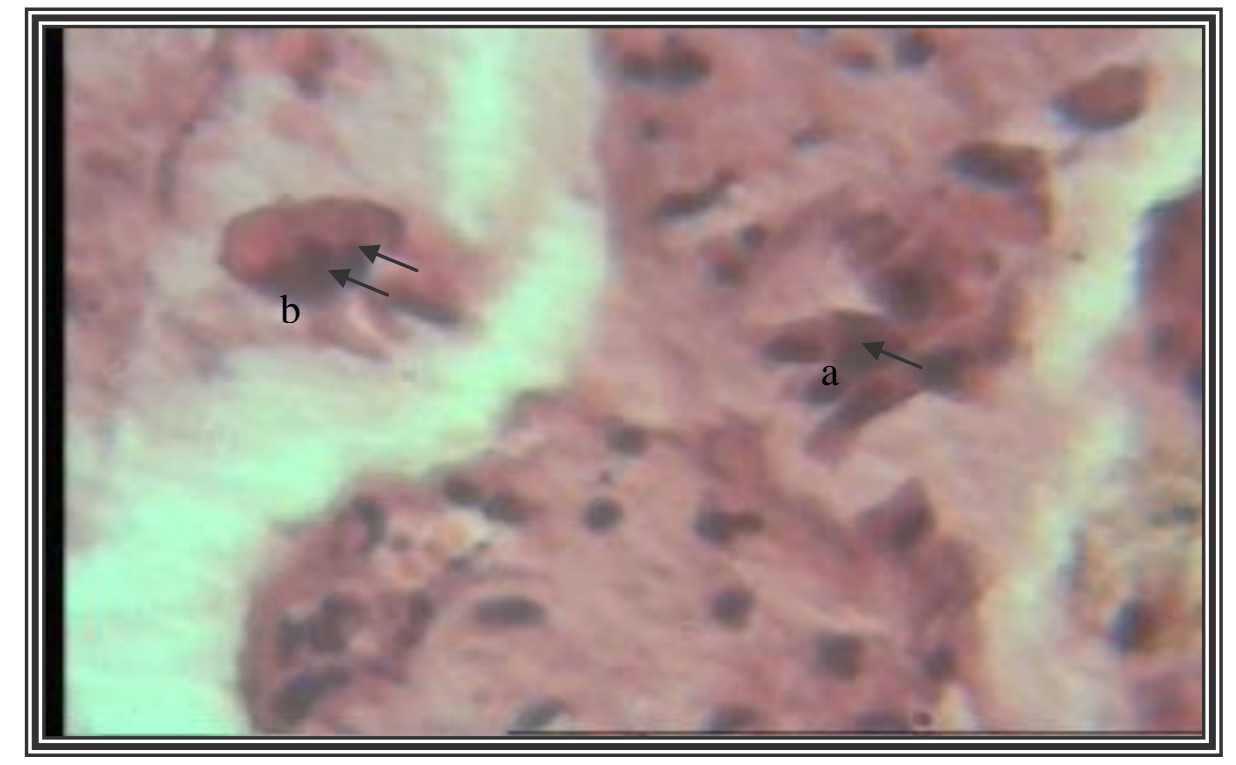

Fig 6: Histological section from Retained Placenta of buffalo revealed proliferation of mononuclear inflammatory cells (a) associated with binucleated cells in intervillous connective tissue (b). H\&E 1000X

\section{References}

1.Takagi M, Fujimoto S, Ohtani M, Miyamoto A, Wijagunawardane $\operatorname{MPB}(2002)$. Bovine retained placenta. Hormonal concentrations in fetal and maternal placenta. Placenta 23: 429-437.

2.Sundals WCD, Curis RA, Cote Fj.( 1979) The effects of retained placenta and metritis complex on reproductive performance. Cand Vet J; 20: 131135.

3.Rahawy MA.(2006) Reproductive disorders in Iraqi buffalo cows in Ninavah province. The $4^{\text {th }}$ scientific conference college of Veterinary Medicine, University of Mosul: 89-96.

4.Azawi, O.I(2006) Clinical, bacteriological and pathological studies of uterine infections of Iraqi buffalo cows. $\mathrm{PhD}$. Thesis, College of Veterinary Medicine, University of Baghdad, Baghdad,: 45-138.

5.Magieed AF.( 2001) Postpartum leucocytic activity and retained placenta in cattle. Iraqi J Vet Sci; 14: 133-136.
6.Culling CFA, Allison RT, Barr WT. (1985) Cellular pathology Technique. London: Butter Worths: 155-163.

7.Noakes DE, Parkinson TJ, England GC.(2001) Arthur s Veterinary Reproduction and Obstetrics. $8^{\text {th }}$ ed., Philadelphia: Saunders: 412.

8.William WF, Margolis MJ, Manspeaker JE, Douglass LW, Davidson JP.(1987) Peripartum changes in the bovine placenta related to fetal membrane retention. Theriogenology 28: 218-223.

9.Al-Sadi HI, Magieed AF, Ridha AM.(1994) Histopathology of retained bovine fetal membrane. Theriogenology 42: 273-278.

10. Laven RH, Peters AR.(1996) Bovine retained placenta, Etiology, Pathogenesis and Economic loss. Vet Rec 139: 465-471.

11. Lyes J.(1996) Initiation of parturition. Anim Reprod Sci 42: 495-503.

12. Yallampalli C, Garfield RE.(1994) Uterine contractile responses to endothelin-1 and endothelin 
receptor are elevated during labor. Biol Reprod 51: 640-645.

13. Schausor $\mathrm{KH}$, Nielsea $\mathrm{AH}$, Winther $\mathrm{H}$, Dantze V, Poulsen K.(1998) Auto radiographic localization and characterization of angiotensin receptors in the bovine, placenta and fetal membrane. Biol Reprod 59: 684-692.

14. Kimura K, Goff JP, Kehrli ME, Reinhardl TA.(2002) Decreased neutrophil function as a case of retained placenta in dairy cattle. $\mathbf{J}$ Dairy Sci 85: 549-550.

15. Kimura K, Goff JP.(2002) Retained Placenta and Immune System. J Dairy Sci 85: 544.

16. Kankofer M., Lipko K, Zdunczk S(2005) Total antioxidant capacity of bovine spontaneously released and retained placenta. Pathophysiology 11: $215-219$.

\section{دراسة سريرية ومرضية لاحتباس المشيمة في الجاموس العراقي$$
\text { انتصار رحيم الكناني }
$$ \\ الخلاصة}

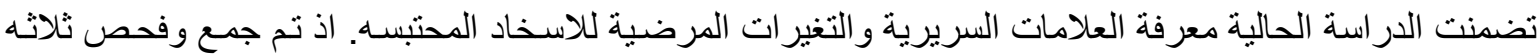

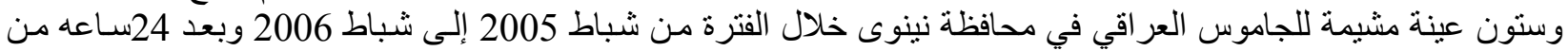

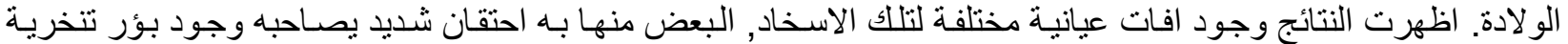

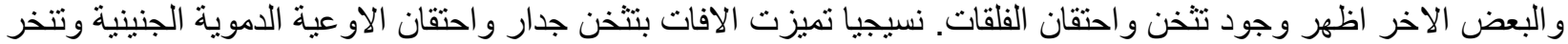

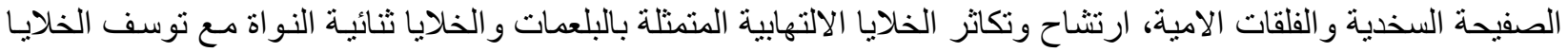

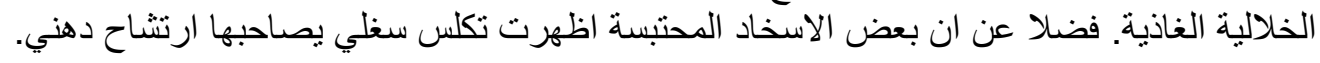

